\title{
Supply Chain Responsiveness Through Modularity Based Manufacturing Practices: An Exploratory Study
}

Ashish A. Thatte, Ph.D., Gonzaga University, USA

\begin{abstract}
Modularity based practices have long been said to improve flexibility of firms. This study extends prior research on manufacturing practices by exploring the dimension level and item level relationships between modularity based manufacturing practices and supply chain responsiveness. A large scale web-based survey yielded 294 responses from industry professionals in the manufacturing and supply chain area. The proposed relationship was first tested using structural equation modeling using AMOS, followed by regression analyses for exploring dimension and item level relationships. The study indicates that firms with high levels of modularity based manufacturing practices have high levels of supply chain responsiveness. Key modularity based manufacturing practices that improve various aspects of supply chain responsiveness are identified and discussed.
\end{abstract}

Keywords: Modularity Based Manufacturing Practices; Supply Chain Responsiveness; Structural Equation Modeling

\section{INTRODUCTION}

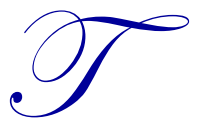

oday's manufacturing organizations are successful if they accurately anticipate market trends and quickly respond to changing customer needs (Stalk et al., 1992), with innovative products and improved manufacturing processes. Modularity practices (modular products, processes, and organizational architectures) have long been talked about as effective means to cope with demand uncertainty (Tu et al., 2004). Many empirical questions regarding the managerial and organizational implications of modularity-based manufacturing are still left unanswered (Ulrich, 1995). Since supply chains compete with one another in today's global markets (Christopher and Peck, 2004; Li et al., 2005), it would be useful to empirically explore the true influence of modularity-based manufacturing practices on a supply chain's ability to be responsive. The extant literature does not address what modularity practices have a greater impact on the responsiveness of a supply chain. The research question addresses what modularity based manufacturing practices are indeed important to improve various facets of supply chain responsiveness:

RQ: What modularity based manufacturing practices affect supply chain responsiveness and its dimensions?

The relationship between the two constructs is first tested empirically, using data collected from 294 respondents to a survey questionnaire, using AMOS structural equation modeling. Specific modularity based practices instrumental in improving supply chain responsiveness are identified using regression analyses.

The remainder of the paper is organized as follows. Section 2 presents the research framework, provides definitions and theory underlying each dimension of modularity based manufacturing practices and supply chain responsiveness, and develops a hypothesized relationship. Research methodology for large scale data collection is described in section 3. Section 4 presents the results for reliability analysis, predictive validity, hypothesis testing, and multiple regression analyses. Sections 5 and 6, discuss research findings and research implications respectively, while limitations of the study and directions for future research are provided in Section 7. 


\section{RESEARCH FRAMEWORK}

The research framework shown in Figure 1, proposes that modularity based manufacturing practices (MBMP) have a direct impact on supply chain responsiveness (SCR).

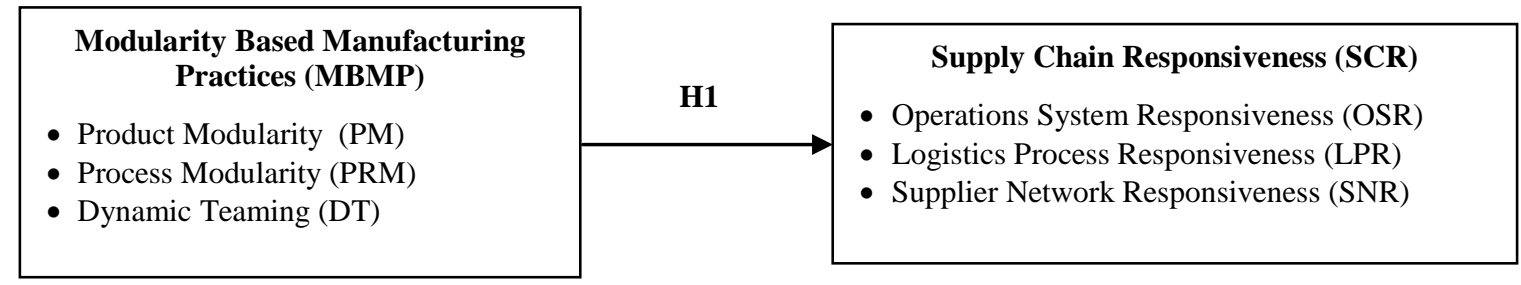

Figure 1. Research framework

Modularity based manufacturing practices (Tu et al., 2004) and supply chain responsiveness (Thatte et al., 2012) are concepts operationalized in past research. Expected relationship between MBMP and SCR is briefly discussed with supporting literature review in the following paragraphs. A hypothesis relating these variables is further developed.

\subsection{Modularity based manufacturing practices (MBMP)}

Modules are defined as units in a large system that are structurally independent of one another, but functionally integrated (Baldwin and Clark, 2000). A complex system can be easily managed by dividing it into smaller modules and examining each piece separately. Modularity refers to "the degree to which a system's components can be separated and recombined" into new configurations with little loss of functionality (Schilling, 2000, p. 12; Schilling and Steensma, 2001). Modularization involves organizing complex products and processes efficiently (Baldwin and Clark, 1997), by breaking down large jobs into simpler parts so they can be "managed independently and yet operate together as a whole" (Mikkola and Larsen, 2004, p. 441). MBMP is defined as the application of unit standardization or substitution principles to product design, production process design, and organizational design (Tu et al., 2004; Ulrich, 1995). MBMP are a set of actions that enable firms to achieve modularity in products, processes, and organizations (Tu et al., 2004).

Several powerful forces are behind modularization: (1) the rate of technological change is accelerating, (2) customers, empowered by advanced computing and networking technologies, are demanding greater product variety at lower prices, and (3) technology-intensive products are becoming more complex (O’Grady, 1999).

The potential benefits of modularity include economies of scale, increased feasibility of product/components change, increased product variety and reduced lead time, decoupling tasks and ease of product upgrade, maintenance, repair, and disposal (Coronado et al., 2004). The concept of modularity is commanding increasing attention from researchers because of its capability to cope with a turbulent manufacturing environment (Tu, 1999). One of the key principles that will determine the factory of the future is the modular organization of manufacturing processes (Drucker, 1990), which promises to combine the advantages of standardization and flexibility.

Research in operations management and management science has highlighted that modularity in product design may allow for the design of a loosely coupled production system in which different subassemblies can be made independently, and then rapidly assembled together in different ways, to build the final product configurations (Ernst and Kamrad, 2000; Novak and Eppinger, 2001), thus reducing order lead times.

A limited amount of empirical research has been done to study the effects of MBMP on responsiveness of organizations. A careful literature review indicates that research on modularity-based manufacturing is scattered and mostly descriptive (Tu et al., 2004). Only a few existing empirical studies (ex: Jacobs et al., 2011) focus on product and process modularity. Existing literature overlooks for the most part, the implications of process modularity and organizational design (Tu et al., 2004). 
Many companies have found that modularity has the potential to revolutionize their entire operation (O’Grady, 1999). Software developers such as Oracle and SAP deliver a wide selection of software modules or "cartridges" that make it easier for companies to create custom applications (Marshall, 1996). IBM prototyped a modular storage system called "Collective Intelligent Brick" that is easily scalable by stacking storage cubes (Zimmerman, 2003). Baldwin and Clark (1997) cite the computer industry as the pioneer in promoting modularity.

Tu et al. (2004) define the construct MBMP, and develop a valid and reliable instrument to measure MBMP. This instrument is adopted in this study. Tu et al. (2004) develop three dimensions of MBMP, namely product modularity, process modularity, and dynamic teaming.

Product modularity $(P M)$ : PM is defined as "the practice of using standardized product modules so they can be easily reassembled / rearranged into different functional forms, or shared across different product lines" (Tu et al., 2004, p. 151). Ulrich and Tung (1991) defined several basic types of modularity, including component sharing (the same module is used across multiple products), component swapping (different components are paired with the same basic product), mix modularity (mix different modules to form a new product), and bus modularity (new options can be added to a standard base by attaching new modules). The key to successful PM is product architecture, a scheme by which functional elements of a product are allocated to structurally independent physical components (Ulrich, 1995; Sanchez, 2000). An effective architecture is created when the interfaces between functional components are standardized and specified, in order to allow substitution of a range of components without requiring changes in the design of other components (Garud \& Kumaraswamy, 1995; Sanchez \& Mahoney, 1996; Sanchez and Collins, 2001). Baldwin and Clark (1997) regard modularity as an emerging revolution as complex products can be built from "smaller subsystems" (p. 84) that are designed and manufactured independently and yet can "function together as a whole" (p. 84). PM not only allows sharing of modules across product lines, but also reduces the volume of parts delivered to the assembly plant. "The results being, better-integrated designs with more value to the customer, an integrated quality focus, and reduced piece cost and investment" (Suzik, 1999).

Swaminathan (2001), however adds that too much part commonality can reduce product differentiation in the eyes of the customer, leading to an effect called cannibalization. Robertson and Ulrich (1998) differentiate external use standard parts from internal use and emphasize that an increase in the internal commonality does not contribute as much toward the cannibalization effect. For example, cannibalization effects are minimal if commonality is introduced in wire harness hidden under the upholstery for a manufacturer's different car models, due to not being easily noticed by customers. On the other hand, cannibalization effect is greater if dashboards are standardized (Swaminathan, 2001).

Process modularity (PRM): PRM is defined as "the practice of standardizing manufacturing process modules so that they can be re-sequenced easily or new modules can be added quickly in response to changing product requirements" (Tu et al., 2004, p. 151). Feitzinger and Lee (1997) suggested that PRM is based on three principles, namely, process standardization, which involves breaking down a process into standard sub-processes that produce standard base units and customization sub-processes that further customize the base units; process re-sequencing, which comprises reordering sub-processes so that standard sub-processes occur first while customization subprocesses occur last (ex: Benetton case of re-sequencing knitting and dyeing of sweaters); and process postponement, which consists of postponing customization sub-processes until a customer order is received or placing of those sub-processes in distribution centers in order to achieve maximum flexibility. Sanchez (1999) echoed similar thoughts of "late-point differentiation of products" using modular architecture. According to Pine et al. (1993), the traditional tightly coupled production processes should be broken apart and modularized. An increasing number of manufacturers are starting to use modular assembly lines where workstations and conveyor units can be added, removed, or rearranged, to create different process capabilities (Cooper, 1999).

A modular process is one where each product can be processed differently and stored in a semi-finished form. These products differ from each other based on the subset of operations that are performed on them (Swaminathan, 2001). Any assemble to order process would classify as modular. The integrated circuits part of the semiconductor wafer fabrication process is modular in nature, "since the type of chip produced depends on the unique subset of operations performed on it" (Swaminathan, 2001, p. 128). On the other hand, oil refining is a nonmodular process as inventory cannot be stored in semi-finished form once the refining process starts. According to 
Swaminathan (2001), modular products are not necessarily always made using modular processes. Biotech and pharmaceutical industries make modular products, but use non-modular processes (Swaminathan, 2001). Many products in these industries can be derived by varying the mix of a small number of ingredients, which makes them modular. They are made in continuous flow processes, making inventory storage of semi-finished items difficult. PRM has the potential to reengineer supply chains, to enhance product customization. Van Hoek and Weken (1998) specifically studied the role of postponed purchasing and manufacturing in a supply chain context. Postponed purchasing requires that suppliers manage part of the inbound complexity associated with material flows by providing standardized modules. Postponed manufacturing extends the final modular assembly into distribution centers or customer sites. The result is a more responsive supply chain that can satisfy individual customer needs without incurring higher production and inventory costs.

Dynamic teaming (DT): DT is defined as "the practice of using modular structures to reorganize manufacturing teams quickly and link them to necessary resources in response to product design or manufacturing process changes" (Tu et al., 2004, p. 152). It is the application of modularity principles to human resource management and organizational process design in manufacturing organizations. Today's rapidly changing manufacturing environment requires a dynamic team structure that is different from traditional cross-functional teams. Pine et al. (1993) argue that cross-functional teams are usually tightly integrated to improve efficiency, but lack flexibility. To achieve flexibility, companies should break apart tightly coupled teams and form loosely coupled networks of modular, flexible working units, so that these groups of employees, processes, and technology can be easily reconfigured within an organization, to cope with ever changing customer needs.

Galunic and Eisenhardt (2001) investigated a similar concept of modular organizational form, termed "dynamic community." They envisage corporate divisions and project teams as dynamic modules with distinctive capabilities, responsibilities, and resources that can be reconfigured to create new productive entities with shared culture and values that can adapt quickly to changing environments. Schilling and Steensma (2001) studied the adoption of modular organizational forms at the industry level. Their study included contract manufacturing (quickly adding temporary manufacturing capacity modules by contract), alternative work arrangements (employing workers on a short-term contract basis), and alliances (accessing critical capabilities the company lacks in-house through partnership with other firms). These practices are expected to generate more flexibility in manufacturing systems. Hoogeweegen et al. (1999) introduced the modular network design concept to explain how computer information technology enables virtual organizations to effectively reallocate production tasks and resources among modular virtual teams to cut costs and throughput time. Similar researches on DT at different levels of analyses, contribute to the general modular systems theory.

Ketchen and Hult (2002) add that today's managers face an array of complex challenges, which requires them to keep pace with technological progress and cope with global competition. They further maintain that a modular form of organization is one tool to deal with these challenges. The authors compare modular organizational form with home building. A traditional home is a stable, cohesive object. Homes take a long time to build and once in place, adding to or otherwise modifying the home's basic structure requires a major effort. In contrast, modular homes can be readily assembled, broken apart, and reassembled to meet owner needs.

Daft and Lewin (1993) assert that there is an increasing trend of moving away from hierarchical and bureaucratic organizations that provide centralized control over activities. They further add that the shift is towards more flexible, learning organizations that continuously change and adapt to changes. These organizations are said to "solve problems through interconnected coordinated self-organizing processes" (p. i) and teams, and which has been termed as 'dynamic teams' in this study. The dynamic teams are characterized by an ability to adapt and create change (i.e. highly flexible to adapt to change), that more fully use both human and technological resources, and that are global in scope (Daft and Lewin, 1993).

\subsection{Supply chain responsiveness (SCR)}

SCR is defined as the capability of promptness and the degree to which the supply chain can address changes in customer demand (Thatte et al., 2012). This responsiveness is aggregate of the operations system, logistics process, and supplier network responsiveness. In a rapidly changing competitive world, there is a need to 
develop organizations and supply chains that are significantly more flexible and responsive than existing ones (Gould 1997, James-Moore, 1996). Although it would be interesting to study SCR from the supply disruption perspective, the current study focuses on customer demand perspective. Thatte et al. (2012) define the construct SCR, and develop a valid and reliable instrument to measure the construct. The same instrument is adopted in this study. Thatte et al. (2012) develop and validate three dimensions of SCR, namely operations system responsiveness, logistics process responsiveness, and supplier network responsiveness.

Operations system responsiveness (OSR): OSR is defined as the ability of a firm's manufacturing system to address changes in customer demand (Thatte et al., 2012). OSR includes both manufacturing and service operations. It would also include the ability to rapidly configure or reconfigure assets and operations of a manufacturing system to cope with consumer trends (Wu, 2001; Lummus et al., 2003), respond rapidly to changes in product volume, and effectively expedite emergency customer orders. As a supply chain responds to customer demand, the constituent organizations may be required to move quickly from producing one product to another, or quickly change production levels for a given product. From a manufacturing standpoint, the responsiveness of an operations system would be an ability of the manufacturing or production function to respond rapidly to unexpected events, and an ability to swiftly accommodate special or non-routine customer requests. Operations responsiveness at each node in a supply chain is an integral component of SCR, since each entity in a supply chain is required to deliver the product or service in a timely and reliable manner, to satisfy customer demand (Duclos et al., 2003; Lummus et al., 2003).

The items under this category measure the responsiveness associated with a specific node or firm in a supply chain (Duclos et al., 2003; Lummus et al., 2003). This firm could be a supplier, manufacturer, or customer, or distributor. Anderson and Lee (2000) identify operations responsiveness as a valuable component of a successful supply chain strategy. Flexibility and speed of response are essential ingredients of a firm's manufacturing system (Holweg 2005; Holweg and Pil, 2001; Meehan and Dawson, 2002; Williamson, 1991). Measures used to operationalize the OSR construct are: operations system's ability to - respond rapidly to changes in product volume demanded by customers, effectively expedite emergency customer orders, rapidly reconfigure equipment to address demand changes, rapidly reallocate people to address demand changes, and rapidly adjust capacity to address demand changes.

Logistics process responsiveness (LPR): LPR is defined as the ability of a firm's outbound transportation, distribution, and warehousing system (including 3PL/4PL) to address changes in customer demand (Thatte et al., 2012). Logistics and distribution management includes the activities of transportation of goods from suppliers to manufacturer to distribution centers to final points of consumption (Ricker and Kalakota, 1999; Duclos et al., 2003; Lummus et al., 2003). These activities include warehousing, packaging and shipping, transportation planning and management, inventory management, reverse logistics, and order tracking and delivery. This study focuses on the outbound logistics of the focal firm. Fuller et al. (1993) suggest that a firm's logistics system is instrumental in creating value for its customers. This value creation implies ensuring logistics flexibility (Duclos et al., 2003; Lummus et al., 2003) and speed within the supply chain to serve each distinct customer's needs. A typical response to uncertainty is to build flexibility into the supply chain (Simchi-Levi et al., 2008). Organizations can minimize risk and stay competitive (Simchi-Levi et al., 2008) if flexibility can be supplemented by an increased velocity of sensing and responding. This responsiveness in the logistic processes is a vital component in the success of a responsive supply chain strategy (Fawcett, 1992).

The responsiveness components in the logistics system include - selecting logistics components that: accommodate and respond to wide swings in demand over short periods, adjust warehouse capacity to address demand changes, handle a wide range of products, vary transportation carriers, have the ability to pack product-intransit to suit discreet customers' requirements, and have the ability to customize products close to the customer. It is vital that a firm has easy access to and is able to utilize different modes of transportation to be logistically responsive (Prater et al., 2001). Hise (1995) states that companies need a capability and flexibility to adjust logistic systems quickly to respond to changes in market needs, and the necessitated product assortment. Measures used to operationalize the LPR construct are: logistics system's ability to - rapidly respond to unexpected demand changes, rapidly adjust warehouse capacity to address demand changes, rapidly vary transportation carriers to address demand changes, and effectively deliver expedited shipments. 
Supplier network responsiveness (SNR): SNR is defined as the ability of a firm's major suppliers to address changes in the firm's demand (Thatte et al., 2012). A key to responsiveness is the presence of responsive partners upstream and downstream of the focal firm (Christopher and Peck, 2004). Reichhart and Holweg (2007) argue that suppliers' manufacturing systems' responsiveness can be treated as the supply chain's responsiveness. The ability of a firm to react quickly to customer demand is much dependent on the reaction time of its suppliers to address the firm's demand. Thus, responsive firms should be able to select suppliers who can add new products and make desired changes, quickly. Supply chains should be capable and ready to address ripple effects caused by new technologies, terrorist threats (Walker, 2005) or increased competition. Slack (1991) argues that supplier networks are the essential building blocks of a flexible system. Some interviews with operations managers conducted at the European vehicle assembly plants of Volvo revealed that the lack of supplier network flexibility hampered the company's responsiveness (Holweg, 2005). Supplier network flexibility (Slack, 1991) and thus SNR is an important part of SCR. Holweg and Pil (2001) argue that flexibility in the supplier network is an important ingredient of being responsive to changes in customer demand.

Responsive suppliers are a vital resource of a firm when design (McGinnis and Vallopra, 1999; Burt and Soukup, 1985) and manufacturing of outsourced products are involved. Fisher et al. (2000) found that for short lifecycle products, such as fashion apparel, retailers are most successful if they can work with suppliers who can provide initial shipments of products based on forecasts, but then rapidly increase production to the right style, color, size, etc. based on actual sales. Choi and Hartley (1996) found that the capability of suppliers to make product volume changes to be a significant factor in supplier selection in the automotive industry. In the electronics industry, for example, demand volatility poses a unique challenge to suppliers to vary output in line with demand. The increases or decreases in demand may come at a short notice and may need to be sustained over some time period. SNR measures used in the study are: major suppliers' ability to - change product mix in a relatively short time, consistently accommodate the customer-firm's requests, provide quick inbound logistics to its customer-firms, and effectively expedite emergency orders.

\subsection{Research hypothesis}

The literature advocates that effective modularity practices are essential and vital for attaining cost effective responsiveness (Feitzinger and Lee, 1997; Gunasekaran and Yusuf, 2002; Abair, 1997; Sharifi, 1998; Van Hoek et al., 2001; McCutcheon and Raturi, 1994; Kidd, 1994) as they provide standardized interfaces capable of being customized by adding different modules, thereby offering a wide variety of products in a short time (Lee et al., 1993; Sanchez, 1999). Further, modular products can be disaggregated and recombined into new configurations with little loss of functionality. This provides organizations the ability to rapidly configure a variety of products as customer demand changes, with a lead time equal to that dictated by final assembly process near to the customer (Ulrich, 1995), thereby reducing uncertainty and complexity (Sanchez, 2000; Baldwin and Clark, 1997; Baldwin and Clark, 2000). A complex system can thus be easily managed by dividing it into smaller modules and examining each piece separately. Thus, designing products so that they share common parts (i.e. product modularity) and processes (i.e. process modularity) initially and differ substantially only by the end of the production process is one of the most important ways to respond quickly to demand fluctuations, since it allows the firms to finish products only when they have accurate information on consumer preferences (Lee, 2004).

Product modularity provides suppliers with a responsiveness that is needed to cater to demand changes, due to being able to customize products quickly and inexpensively (Feitzinger and Lee, 1997; Hopwood, 1995; Mikkola and Larsen, 2004; Salvador et al., 2002). For designers and manufacturers, product modularity provides flexibility to respond to uncertainties (Baldwin and Clark, 1997), whereas process modularity enables them to handle increasingly complex technology (Tu, 1999). Process modularity allows re-sequencing and adding of new process modules to customize the products, in response to changing customer demand (Tu et al., 2004). Modularity in products and processes lead to a responsive supply chain that can satisfy individual customer needs without incurring higher production and inventory costs (Yang et al., 2004; Van Hoek and Weken, 1998; Tu et al., 2004). Jacobs et al. (2011) found product modularity and process modularity to be antecedents of manufacturing agility. The computer industry has dramatically increased its rate of innovation through the use of modular designs. Baldwin and Clark (1997) regard modularity as a "strategy for organizing complex products and processes efficiently" (p. 86). They argue that it is modularity, more than any other technology that makes the rapid developments in computer industry possible. 
Modularity allows manufacturers (ex: Dell, HP, Motorola, Toyota, National Bicycle, Benetton) to handle increasingly complex technologies, respond faster to changing customer demand (Tu et al., 2004), and adapt to uncertainties in business environment

Modular architectures minimize the physical changes that are needed to achieve a functional change (Mikkola, 2003), thus enabling quick customer response. Dell delivers a customized PC within a few days of receiving the order. Proctor and Gamble once offered 13 different product designs in their pamper phases line to reflect the change in infants as they grow from newborns to toddlers (Pine, 1999). Use of modular practices for its LaserJet printer, allowed HP to improve customer responsiveness (Feitzinger and Lee, 1997; Prater et al., 2001) Ford, GM, and VW have introduced modular assembly lines and modular cars to improve responsiveness in manufacturing. Modular design has also been an important factor in Microsoft's on-time delivery of its extremely complex Windows operating systems (Eisenhardt \& Brown, 1998). Baldwin and Clark $(1997,2000)$ argue that it is modularity, more than any other technology that makes rapid developments in computer industry possible.

Although the principles of modular production have been discussed for decades (Starr, 1965; Ulrich \& Tung, 1991), their strategic potentials are only recently being rediscovered by many leading manufacturers as they seek improved responsiveness to compete in an increasingly uncertain marketplace (Sanchez and Collins, 2001; Ketchen and Hult, 2002; Pine et al., 1993). Drucker (1990) had predicted that the factory of 1999 would be highly modular, which would allow rapid product changes and rapid response to market demands. Modularity can lead to lower product development lead time and lower project completion time (Ulrich, 1995), along with lower cycle time (Lorenzi and Lello, 2001).

Firms that can reorganize and reconfigure teams quickly and efficiently are capable of being responsive while maintaining high quality in product design and process execution (Tu et al., 2004). When companies form loosely coupled networks of modular, flexible working units, instead of tightly coupled teams, these groups of people, processes, and technologies can be reconfigured with ease, in order to meet customer demand (Weick, 1990; Tu et al., 2004). Thus, modularity improves the responsiveness of a firm's operations system. Further, traditional organizations have fairly stable boundaries, while modular organizations can quickly be recast as needed as per the task, thereby improving flexibility (Ketchen and Hult, 2002) and speed of responding to changes in business environment. MBMP thus results in overall SCR. The above arguments lead to:

Hypothesis 1: Firms with high levels of modularity based manufacturing practices will have high levels of supply chain responsiveness.

\section{RESEARCH METHODOLOGY}

This section describes the research method for large-scale data collection. Valid and reliable instruments for supply chain responsiveness (Thatte et al., 2012) and modularity based manufacturing practices (Tu et al., 2004) have been adopted from respective literatures. The items for these instruments are listed in Appendix A. Since modularity practices and responsiveness are dependent on the individual operating firms within a supply chain, the unit of analysis in this study is a firm. Also a study that encompasses the entire supply chain domain, from raw materials through production/assembly at multiple stages/organizations, through delivery via diverse distribution channels, would be complex, time consuming, and costly. Past studies (ex: Swafford et al., 2006a) have used similar unit of analysis. The study extrapolates the results obtained at a firm level to a supply chain level.

\subsection{Large-scale methods}

Since this study has a supply chain management focus, the target respondents were the operations / manufacturing / purchasing / logistics / materials / supply chain - vice presidents, directors and managers as these personnel were deemed to have the best knowledge in the supply chain area. The respondents were asked to refer to their major suppliers or customers when answering the questionnaire. E-mail lists were purchased from three different sources. These were the Council of Supply Chain Management (CSCMP), Rsateleservices.com, and Lead411.com. Seven SIC codes are covered in the study: 22 "Textile Mill products", 23 "Apparel and other Textile Products", 25 "Furniture and Fixtures", 34 "Fabricated Metal Products", 35 "Industrial Machinery and Equipment", 
36 "Electrical and Electronic Equipment", and 37 "Transportation Equipment". The lists were limited to organizations with more than 100 employees as these organizations are most likely to engage in SCM initiatives.

The survey was web-based, based on methods of Dillman (2000). The final version of the questionnaire was administered by e-mail to 5498 target respondents. To ensure a reasonable response rate, the survey was emailed in three waves. In the first e-mail, the questionnaire with the cover letter indicating the purpose and significance of the study was emailed to target respondents. In the cover letter, the respondents were given three options to send their response: 1) online completion and submission: a web link (survey hosted on university website) was given so that they could complete the questionnaire online; 2) download the hard copy online: a link to the questionnaire in .pdf file was given and respondents could send it by fax or ask for a self-addressed stamped envelope; 3) request the hard copy by sending an email: they received in their regular mail a copy of the questionnaire along with a self-addressed stamped envelope. Using this approach data was gathered during JuneJuly 2006.

Response rate was calculated based on the number of click-throughs the emailing generated and total number that was converted to a completed survey. After three waves of emailing a total of 714 click-throughs were generated and 294 completes were obtained to provide a good response rate of $41.18 \%$. Response rate based on the click-throughs may represent a better measure for email surveys, since bulk emails sent out in this manner are treated as spam by respondents' organizations' email program and / or may never be retrieved or viewed by the target respondent. Since it is highly difficult to track such information accurately, a more appropriate measure would be to base the analysis on the number of people who have visited the site and have had an opportunity to review the request and purpose of this study, and then may have declined to complete the survey based on any number of reasons. $11 \%$ of the respondents are CEO/President, $45 \%$ are Vice Presidents, $25 \%$ are Directors, and $19 \%$ are titled as Managers. Thus $81 \%$ of the respondents (CEOs, VPs, and Directors) are high level executives, implying a high reliability of the responses received, as these executives have a wider domain (job responsibility) and administrative knowledge. This is consistent with past survey-based research studies in SCM (ex: Frohlich and Westbrook, 2002). The areas of expertise were $11 \%$ executives (CEOs/Presidents), 12\% purchasing, 22\% SCM, $18 \%$ distribution/transportation/logistics, 20\% manufacturing/production, 10\% materials, and $7 \%$ belong to other category such as sales. Thus the respondents' domains cover all key functions across the supply chain ranging from purchasing, to manufacturing, to sales, to distribution. Also, since 33\% of the respondents have been with the organization over 10 years, $21 \%$ have been at the organization between $6-10$ years, implies that majority of the respondents have a comprehensive view of the supply chain program of their organization.

This research did not investigate non-response bias directly since the email lists had only names and email addresses of individuals without organizational details. This research compares those subjects who responded after the first e-mailing wave and those who responded to the second/third wave. The succeeding waves of survey were considered to be representative of non-respondents (Lambert and Harrington, 1990; Armstrong and Overton, 1977). Similar methodology has also been used in prior SCM empirical research (Li et al., 2005; Chen and Paulraj, 2004; Handfield and Bechtel, 2002). Chi-square tests ( $\chi^{2}$ statistic) were used to make the comparisons. No significant difference in industry type (based on SIC), employment size, and respondent's job title was found between these two groups (i.e. $\mathrm{p}>0.1$, when testing the null hypotheses: there is no significant difference in distribution of responses across SIC codes/employment size/job title between groups). Further, Chi-square tests of independence were also performed to observe if the distribution of responses across SIC codes, employment size, and respondent's job title is independent of the three waves when considered independently. No significant difference in industry type (based on SIC), employment size, and respondent's job title was found between each of the three groups / waves.

\section{RESULTS}

This section discusses reliability analysis, construct level correlation analysis, followed by hypothesis testing, and regression analyses. 


\subsection{Reliability}

The reliabilities of MBMP and SCR are assessed with Cronbach's (1951) alpha. A commonly used value for acceptable reliability is 0.70 (Hair et al., 2005; Nunnally, 1978). Table 1a-b reports means, standard deviations, correlations, and reliabilities for the constructs. The reliability values for all constructs are greater than 0.80 , which is considered to be good.

Table 1 Means, standard deviations, correlations, and reliabilities of (a) MBMP; and (b) SCR

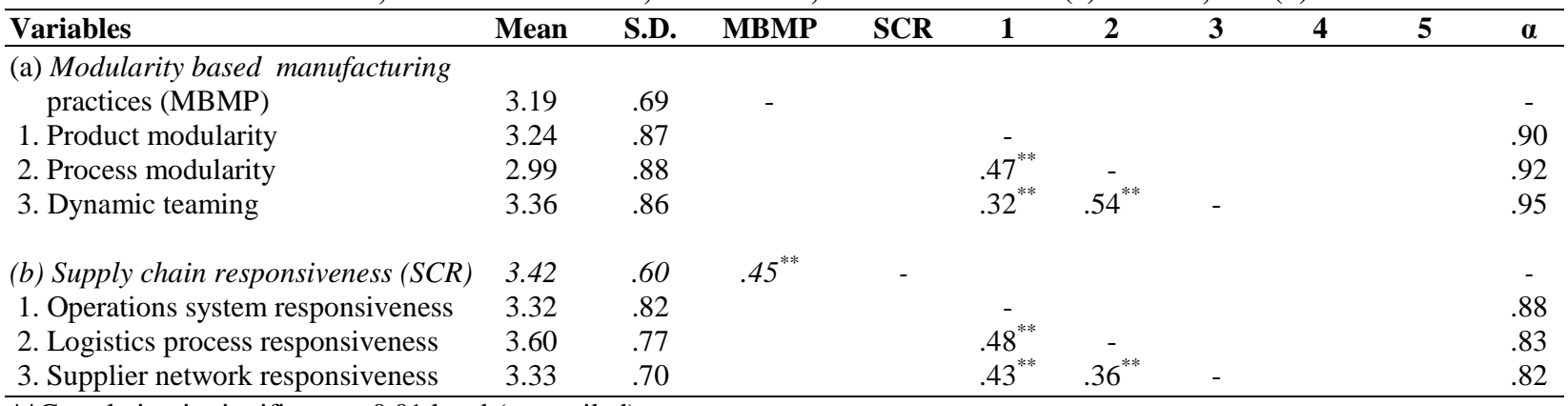

**Correlation is significant at 0.01 level (two-tailed).

\subsection{Predictive validity}

For purposes of generalizability of measurement, predictive validity or criterion-related validity is performed by comparing the second order factor models with one or more external variables (criterion) known or believed to measure the attribute. Criterion-related validity is characterized by prediction to an outside criterion and by checking a measuring instrument, against some outcome or measure (Kerlinger, 1986). In this study, the criterion used to test the predictive validity is dependent variable. Construct level correlation analysis is performed between the second order constructs to check for preliminary statistical validity of the hypothesis. Both second-order constructs MBMP and SCR were represented by a composite score. Both MBMP and SCR are measured by three first-order constructs or dimensions and each dimension contains multiple items. An average of the score for all items measuring each dimension was treated as a score for the corresponding dimension. Further, an average of the score for all dimensions that comprise the second-order construct was treated as the composite score for the secondorder construct. Pearson correlation was then run between these higher order constructs. Table 1 provides results of correlation analyses for second-order constructs MBMP and SCR. All correlations are statistically significant at 0.01 level. Thus hypothesis 1 is statistically supported by Pearson correlation. Hypothesis testing using AMOS structural equation modeling is discussed in the following section.

\subsection{Hypotheses testing}

AMOS structural modeling method was used to test the relationship between MBMP and SCR. Figure 2 displays AMOS path analyses results. The composite scores for corresponding dimensions were used as input to the structural model. The results are presented in Table 2. The $\chi^{2}$ measure is often criticized for its over-sensitivity to sample size, hence caution is recommended when making inferences pertaining to model fit based on chi-square values alone (Hair et al., 2005). A standardized structural coefficient (or effect size) of 0.371 (indicating $13.8 \%$ of variance in the dependent variable that is accounted by the independent variable) or above is considered large, between 0.100 and 0.371 is considered medium, and 0.1 and below is considered small (Cohen, 1988; 1990). The results exhibit that all measurements have significant loadings to their corresponding second-order construct. Overall the model has good fit with $\chi^{2}=20.57, \mathrm{df}=8, P=0.008, \mathrm{NFI}=0.952, \mathrm{GFI}=0.98$, AGFI $=0.94$, and CFI $=$ 0.97. RMSEA is 0.07 , and is within the recommended range of acceptability $(<0.05$ to 0.08$)$. The hypothesis testing results are discussed below.

Hypothesis 1 (t-value $=7.85)$ is found to be significant at $P<0.001$ level, and is thus supported by AMOS structural modeling results. Also, hypotheses $1(\beta=0.67)$ has a large effect size (i.e. standardized coefficient, $\beta>$ 0.37), confirming that the supported relationship between MBMP and SCR, has both statistical and practical significance, and which is instrumental in providing theoretical and managerial implications. 
Table 2 Results for structural model

\begin{tabular}{cccccr}
\hline Hypothesis & Relationship & $\begin{array}{c}\text { Total effects } \\
\beta \text { (t-value) }\end{array}$ & $\begin{array}{c}\text { Direct effects } \\
\beta \text { (t-value) }\end{array}$ & $\begin{array}{c}\text { Indirect effects } \\
\beta \text { (t-value) }\end{array}$ & Hypothesis \\
\hline $\mathrm{H} 1$ & $\mathrm{MBMP} \rightarrow \mathrm{SCR}$ & $0.67 * *(7.85)$ & $0.67 * *(7.85)$ & - & Supported \\
\hline
\end{tabular}

** Significant at $P<0.001$ level

Hypothesis 1, which states that organizations with high levels of MBMP will have high levels of SCR is strongly supported $(\beta=0.67, P<0.001, \mathrm{t}=7.85)$, making it evident that MBMP may directly and positively influence responsiveness of a supply chain. Hypothesis 1 confirms that modular products, processes, and production teams allow easy reconfiguration thus improving a firm's ability to adapt to and address changes in customer demand and / or business environment.

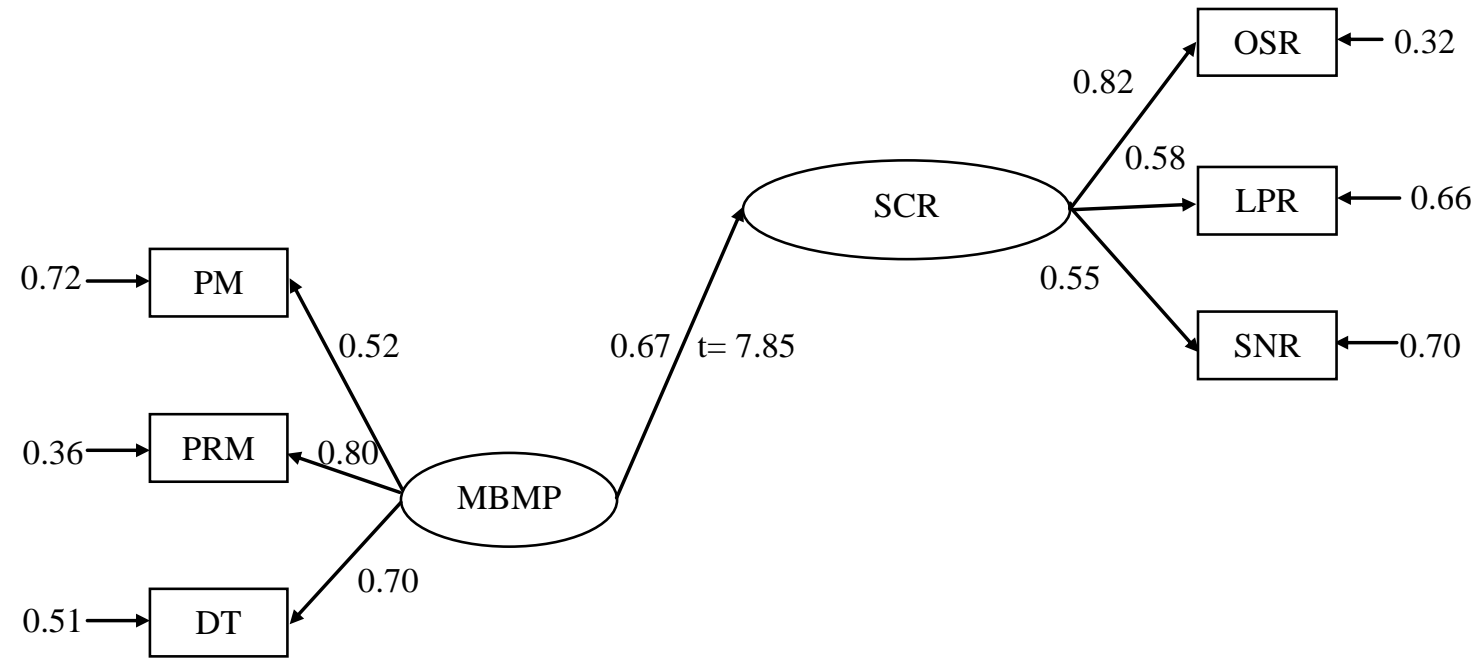

$\mathrm{RMSEA}=0.07, \mathrm{NFI}=0.952, \mathrm{GFI}=0.98, \mathrm{AGFI}=0.94, \mathrm{CFI}=0.97$

Figure 2. AMOS structural model of MBMP and SCR

\subsection{Dimension-level regression analyses}

This study explores as to which specific individual dimensions of MBMP (i.e. PM, PRM, and DT) make meaningful contributions to the overall prediction of SCR and its dimensions (i.e. OSR, LPR, and SNR). Stepwise multiple regression is often used in studies that are exploratory in nature (Aron and Aron, 2012).

First, a dimension-level analysis using stepwise multiple regression is performed to determine which dimension/s from PM, PRM, and DT significantly predict/s SCR (summated score). Results (Table 3) indicate an overall model of two dimensions of MBMP (namely DT and PRM) that reasonably predict $S C R, \mathrm{R}^{2}=0.249, \mathrm{R}_{\text {adj }}^{2}=$ $0.244, \mathrm{~F}(2,291)=48.324, \mathrm{p}<0.001$. The model accounted for $24.4 \%\left(\mathrm{R}_{\text {adj }}^{2}\right)$ of the variance in SCR. Only two dimensions of MBMP in the order DT $(\beta=0.317)$ and PRM $(\beta=0.250)$, significantly predict SCR (summated score). PM did not contribute significantly to the prediction of SCR. These are interesting findings and shall be more meaningful if analyzed on individual dimensions of SCR.

Table 3 Dimension level stepwise regression results:

Model summary and coefficients for MBMP dimensions on SCR (summated score)

\begin{tabular}{|c|c|c|c|c|c|c|c|c|c|c|c|c|}
\hline Step & $R$ & $R^{2}$ & $\boldsymbol{R}_{a d j}^{2}$ & $\Delta R^{2}$ & $F_{c h g}$ & $p$ & $d f_{1}$ & $d f_{2}$ & $B$ & $\beta$ & $t$ & $p$ \\
\hline 1. DT & 0.453 & 0.205 & 0.202 & 0.205 & 75.354 & $<0.001$ & 1 & 292 & 0.221 & 0.317 & 5.249 & 0.000 \\
\hline 2. PRM & 0.499 & 0.249 & 0.244 & 0.044 & 17.132 & $<0.001$ & 1 & 291 & 0.170 & 0.250 & 4.139 & 0.000 \\
\hline
\end{tabular}


Next, dimension-level analyses (stepwise regression) of PM, PRM, and DT on individual SCR dimensions (OSR, LPR, and SNR) are performed. Results are furnished in Tables 4 through 6.

Table 4 Dimension level stepwise regression results: Model summary and coefficients for MBMP dimensions on OSR

\begin{tabular}{lcccccccccccc}
\hline Step & $\boldsymbol{R}$ & $\boldsymbol{R}^{2}$ & $\boldsymbol{R}_{\text {adj }}^{2}$ & $\Delta \boldsymbol{R}^{2}$ & $\boldsymbol{F}_{\boldsymbol{c h g}}$ & $\boldsymbol{p}$ & $\boldsymbol{d} \boldsymbol{f}_{\boldsymbol{1}}$ & $\boldsymbol{d f}_{\mathbf{2}}$ & $\boldsymbol{B}$ & $\boldsymbol{\beta}$ & $\boldsymbol{t}$ & $\boldsymbol{p}$ \\
\hline 1. DT & 0.476 & 0.227 & 0.224 & 0.227 & 85.747 & $<0.001$ & 1 & 292 & 0.339 & 0.356 & 5.939 & 0.000 \\
2. PRM & 0.512 & 0.262 & 0.257 & 0.035 & 13.743 & $<0.001$ & 1 & 291 & 0.206 & 0.222 & 3.707 & 0.000 \\
\hline
\end{tabular}

Table 4 indicates that only two dimensions of MBMP in the order DT $(\beta=0.356)$ and PRM $(\beta=0.222)$, significantly predict OSR. PM does not contribute significantly to the prediction of OSR. A plausible explanation for this could be that PRM and DT items are very closely associated with shop floor and manufacturing, thereby displaying a positive relationship with OSR. Although, PM is theoretically a strong element that can improve a firm's responsiveness, as it allows firms to manufacture a variety of products from numerous modules, results do not support this point. A plausible explanation being, PM affects 'assembly responsiveness' dimension of SCR, and which has not been considered in this research. In addition, another convincing explanation to this effect is that PM directly impacts postponement, which in turn improves SCR. These relationships may be tested in future research.

With regards to LPR (Table 5), the results are not significant $\left(\mathrm{R}^{2}{ }_{\text {adj }}=0.091\right)$ to draw conclusions. It is desired that $R_{\text {adj }}^{2}$ be at least 0.10 in order to draw any substantial inferences (Mertler and Vannatta, 2009). The study did not find PM, PRM, or DT to predict LPR. A reasonable explanation being, PM, PRM, and DT are more manufacturing and product oriented and within the firm. Outbound logistics is post manufacturing and outside the firm, thereby not being predicted by MBMP dimensions.

Table 5 Dimension level stepwise regression results: Model summary for MBMP dimensions on LPR

\begin{tabular}{lcccccccc}
\hline Step & $\boldsymbol{R}$ & $\boldsymbol{R}^{2}$ & $\boldsymbol{R}_{\text {adj }}^{2}$ & $\Delta \boldsymbol{R}^{2}$ & $\boldsymbol{F}_{\text {ch }}$ & $\boldsymbol{p}$ & $\boldsymbol{d f}_{\boldsymbol{I}}$ & $\boldsymbol{d} \boldsymbol{f}_{2}$ \\
\hline 1. DT & 0.286 & 0.082 & 0.079 & 0.082 & 26.006 & $<0.001$ & 1 & 292 \\
2. PRM & 0.312 & 0.097 & 0.091 & 0.016 & 5.029 & $<0.05$ & 1 & 291 \\
\hline
\end{tabular}

Table 6 Dimension level stepwise regression results: Model summary and coefficients for MBMP dimensions on SNR

\begin{tabular}{|c|c|c|c|c|c|c|c|c|c|c|c|c|}
\hline Step & $R$ & $R^{2}$ & $\boldsymbol{R}_{a d j}^{2}$ & $\Delta R^{2}$ & $F_{c h g}$ & $p$ & $d f_{1}$ & $d f_{2}$ & $B$ & $\beta$ & $t$ & $p$ \\
\hline 1. PRM & 0.313 & 0.098 & 0.095 & 0.098 & 31.603 & $<0.001$ & 1 & 292 & 0.174 & 0.219 & 3.342 & 0.001 \\
\hline 2. DT & 0.345 & 0.119 & 0.113 & 0.021 & 6.956 & $<0.01$ & 1 & 291 & 0.141 & 0.173 & 2.637 & 0.009 \\
\hline
\end{tabular}

Table 6 shows that PRM $(\beta=0.219)$ and DT $(\beta=0.173)$ in that order, significantly predict SNR. PM does not contribute significantly to the prediction of SNR. A close look at PRM items reveals that the intent is to have the process as modules, such that these processes can be rearranged and re-sequenced to create products as per customer demand. Because processes can be re-sequenced, raw materials can be ordered as needed (dictated by the products manufactured by these processes, thus providing organization greater flexibility in terms of sourcing various products), rather than ordering whole products and all at once (i.e. at the beginning of production, had it been a single integrated process). Ordering of materials in small quantities based on process modules can increase suppliers' responsiveness to the focal firm. Item level regression analyses can further explain the effects of DT on SNR. Item level analyses are presented in the following section.

\subsection{Item-level regression analyses}

In order to gain insight into specific practices that impact one or more SCR dimensions, we analyze the effects of specific items constituting significant predictor dimensions DT and PRM, on SCR and its significant dimensions OSR and SNR. Stepwise multiple regression analyses are performed with all items that measure DT and PRM (one predictor dimension items at a time) first on SCR, followed by OSR and SNR. Results are tabulated (Tables 7 through 12) and discussed in the order of significance of predictors of SCR, as evident from the previous section.

DT being the first dimension within MBMP that reasonably predicted SCR (summated score), regression analysis performed (Table 7) to determine the practices within DT that might significantly predict SCR, point to 
DT3 $(\beta=0.329)$ and DT1 $(\beta=0.150)$ in that order, as significant predictors of SCR. DT2, DT4, and DT5 do not contribute significantly to the prediction of SCR.

Table 7 Item-level stepwise regression results: Model summary and coefficients for DT items on SCR (summated score)

\begin{tabular}{lcccccccccccc}
\hline Step & $\boldsymbol{R}$ & $\boldsymbol{R}^{2}$ & $\boldsymbol{R}_{a d j}^{2}$ & $\Delta \boldsymbol{R}^{2}$ & $\boldsymbol{F}_{\boldsymbol{c h g}}$ & $\boldsymbol{p}$ & $\boldsymbol{d} \boldsymbol{f}_{\boldsymbol{I}}$ & $\boldsymbol{d} \boldsymbol{f}_{\mathbf{2}}$ & $\boldsymbol{B}$ & $\boldsymbol{\beta}$ & $\boldsymbol{t}$ & $\boldsymbol{p}$ \\
\hline 1. DT3 & 0.438 & 0.192 & 0.189 & 0.192 & 69.220 & $<0.001$ & 1 & 292 & 0.219 & 0.329 & 4.324 & 0.000 \\
2. DT1 & 0.450 & 0.202 & 0.197 & 0.011 & 3.885 & $<0.05$ & 1 & 291 & 0.090 & 0.150 & 1.971 & 0.05 \\
\hline
\end{tabular}

Similarly, regression analysis results for PRM (second dimension within MBMP predicting SCR) items and SCR, indicate (Table 8$)$ that PRM2 $(\beta=0.294)$ and PRM5 $(\beta=0.182)$ in that order, significantly predict SCR (summated score). PRM1, PRM3, and PRM4 do not significantly predict SCR.

Table 8 Item-level stepwise regression results: Model summary and coefficients for PRM items on SCR (summated score)

\begin{tabular}{lcccccccccccc}
\hline Step & $\boldsymbol{R}$ & $\boldsymbol{R}^{2}$ & $\boldsymbol{R}^{2}{ }_{\boldsymbol{a d j}}$ & $\Delta \boldsymbol{R}^{2}$ & $\boldsymbol{F}_{\boldsymbol{c h g}}$ & $\boldsymbol{p}$ & $\boldsymbol{d} \boldsymbol{f}_{\boldsymbol{1}}$ & $\boldsymbol{d} \boldsymbol{f}_{2}$ & $\boldsymbol{B}$ & $\boldsymbol{\beta}$ & $\boldsymbol{t}$ & $\boldsymbol{p}$ \\
\hline 1. PRM2 & 0.398 & 0.158 & 0.155 & 0.158 & 54.993 & $<0.001$ & 1 & 292 & 0.182 & 0.294 & 4.566 & 0.000 \\
2. PRM5 & 0.425 & 0.181 & 0.175 & 0.023 & 8.007 & $<0.01$ & 1 & 291 & 0.105 & 0.182 & 2.830 & 0.005 \\
\hline
\end{tabular}

Further, regression analyses results of DT (Table 9) and PRM (Table 10) (first and second MBMP dimension respectively, that reasonably predicted OSR) measures (items) and OSR, indicate that DT3 $(\beta=0.267)$ and DT5 $(\beta=0.233)$ in that order, significantly predict OSR. DT1, DT2, and DT4 however, do not contribute significantly to the prediction of OSR. Also, PRM3 $(\beta=0.222)$ and PRM1 $(\beta=0.222)$ together significantly predict OSR. PRM2, PRM4, and PRM5 do not significantly predict OSR.

Table 9 Item-level stepwise regression results: Model Summary and coefficients for DT Items on OSR

\begin{tabular}{lcccccccccccc}
\hline Step & $\boldsymbol{R}$ & $\boldsymbol{R}^{2}$ & $\boldsymbol{R}_{\text {adj }}$ & $\Delta \boldsymbol{R}^{2}$ & $\boldsymbol{F}_{\boldsymbol{c h g}}$ & $\boldsymbol{p}$ & $\boldsymbol{d} \boldsymbol{f}_{\boldsymbol{l}}$ & $\boldsymbol{d f}_{\mathbf{2}}$ & $\boldsymbol{B}$ & $\boldsymbol{\beta}$ & $\boldsymbol{t}$ & $\boldsymbol{p}$ \\
\hline 1. DT3 & 0.461 & 0.213 & 0.210 & 0.213 & 78.991 & $<0.001$ & 1 & 292 & 0.242 & 0.267 & 2.835 & 0.005 \\
2. DT5 & 0.479 & 0.229 & 0.224 & 0.016 & 6.116 & $<0.05$ & 1 & 291 & 0.209 & 0.233 & 2.473 & 0.014 \\
\hline
\end{tabular}

Table 10 Item-level stepwise regression results: Model summary and coefficients for PRM items on OSR

\begin{tabular}{lcccccccccccc}
\hline Step & $\boldsymbol{R}$ & $\boldsymbol{R}^{2}$ & $\boldsymbol{R}_{\text {adj }}^{2}$ & $\Delta \boldsymbol{R}^{2}$ & $\boldsymbol{F}_{\boldsymbol{c h g}}$ & $\boldsymbol{p}$ & $\boldsymbol{d f}_{\boldsymbol{1}}$ & $\boldsymbol{d f}_{\mathbf{2}}$ & $\boldsymbol{B}$ & $\boldsymbol{\beta}$ & $\boldsymbol{t}$ & $\boldsymbol{p}$ \\
\hline 1. PRM3 & 0.397 & 0.158 & 0.155 & 0.158 & 54.631 & $<0.001$ & 1 & 292 & 0.186 & 0.222 & 2.552 & 0.011 \\
2. PRM1 & 0.420 & 0.176 & 0.170 & 0.018 & 6.501 & $<0.05$ & 1 & 291 & 0.177 & 0.222 & 2.550 & 0.011 \\
\hline
\end{tabular}

Finally, regression results for PRM (Table 11) and DT (Table 12) (first and second MBMP dimension respectively, predicting SNR) measures and SNR, indicate that PRM5 $(\beta=0.206)$ and PRM2 $(\beta=0.178)$ in that order, significantly predict SNR. PRM1, PRM3, and PRM4 do not contribute significantly to the prediction of SNR. However, results for DT on SNR (Table 12) are not significant $\left(\mathrm{R}_{\text {adj }}^{2}=0.077\right)$ to draw any substantial inferences, implying that DT items fail to predict SNR.

Table 11 Item-level stepwise regression results: Model summary and coefficients for PRM items on SNR

\begin{tabular}{lcccccccccccc}
\hline Step & $\boldsymbol{R}$ & $\boldsymbol{R}^{2}$ & $\boldsymbol{R}^{2}{ }_{\boldsymbol{a d j}}$ & $\Delta \boldsymbol{R}^{2}$ & $\boldsymbol{F}_{\boldsymbol{c h} \boldsymbol{g}}$ & $\boldsymbol{p}$ & $\boldsymbol{d} \boldsymbol{f}_{\boldsymbol{1}}$ & $\boldsymbol{d f}_{\mathbf{2}}$ & $\boldsymbol{B}$ & $\boldsymbol{\beta}$ & $\boldsymbol{t}$ & $\boldsymbol{p}$ \\
\hline 1. PRM5 & 0.307 & 0.094 & 0.091 & 0.094 & 30.406 & $<0.001$ & 1 & 292 & 0.139 & 0.206 & 3.073 & 0.002 \\
2. PRM2 & 0.340 & 0.116 & 0.110 & 0.022 & 7.088 & $<0.01$ & 1 & 291 & 0.129 & 0.178 & 2.662 & 0.008 \\
\hline
\end{tabular}

Table 12 Item-level stepwise regression results: Model summary for DT items on SNR

\begin{tabular}{lcccccccc}
\hline Step & $\boldsymbol{R}$ & $\boldsymbol{R}^{2}$ & $\boldsymbol{R}^{2}{ }_{\text {adj }}$ & $\Delta \boldsymbol{R}^{2}$ & $\boldsymbol{F}_{\text {chg }}$ & $\boldsymbol{p}$ & $\boldsymbol{d f}_{\boldsymbol{1}}$ & $\boldsymbol{d f}_{2}$ \\
\hline 1. DT4 & 0.283 & 0.080 & 0.077 & 0.080 & 25.936 & $<0.001$ & 1 & 292 \\
\hline
\end{tabular}

A summary of regression analyses results is provided in Table 13. Construct-level stepwise multiple regression analysis result confirms that MBMP reasonably predicts SCR, thus supporting structural equation modeling results and hypothesis 1 . The results point out that DT and PRM are the predominant MBMP that are can improve SCR and its OSR and SNR dimensions. The results neither support PM's influence on SCR and its dimensions, nor support MBMP and its dimensions' influence on LPR. This may be researched in future studies. 
Table 13 Summary of regression analyses results for MBMP and SCR

\begin{tabular}{|c|c|c|c|}
\hline Predictor & Outcome & $\mathbf{R}_{\text {adj }}^{2}$ & Sig. $(p)$ \\
\hline \multicolumn{4}{|c|}{ Construct - Level Regression Analysis } \\
\hline 1. Modularity Based Manufacturing Practices (MBMP) & $\begin{array}{l}\text { Supply Chain } \\
\text { Responsiveness } \\
\text { (SCR) }\end{array}$ & 0.278 & 0.000 \\
\hline \multicolumn{4}{|c|}{ Dimension - Level Regression Analyses } \\
\hline $\begin{array}{ll}\text { MBMP: } & \text { 1. Dynamic Teaming (DT) } \\
& \text { 2. Process Modularity (PRM) }\end{array}$ & $\begin{array}{c}\text { Supply Chain } \\
\text { Responsiveness } \\
\text { (SCR) }\end{array}$ & 0.244 & 0.000 \\
\hline $\begin{array}{ll}\text { MBMP: } & \text { 1. Dynamic Teaming (DT) } \\
& \text { 2. Process Modularity (PRM) } \\
\end{array}$ & $\begin{array}{c}\text { Operations System } \\
\text { Responsiveness (OSR) }\end{array}$ & 0.257 & 0.000 \\
\hline MBMP: $\quad$ Practically NS* & $\begin{array}{l}\text { Logistics Process } \\
\text { Responsiveness } \\
\text { (LPR) }\end{array}$ & 0.091 & 0.000 \\
\hline $\begin{array}{ll}\text { MBMP: } & \text { 1. Process Modularity (PRM) } \\
& \text { 2. Dynamic Teaming (DT) }\end{array}$ & $\begin{array}{l}\text { Supplier Network } \\
\text { Responsiveness } \\
\text { (SNR) }\end{array}$ & 0.113 & 0.000 \\
\hline \multicolumn{4}{|l|}{ Item - Level Regression Analyses } \\
\hline $\begin{array}{l}\text { DT: } \\
\text { 1. DT3 } \\
\text { (reassigning production teams to different production tasks) } \\
\text { 2. DT1 } \\
\text { (using production teams (in the plant) that can be reorganized) }\end{array}$ & \multirow{2}{*}{$\begin{array}{l}\text { Supply Chain } \\
\text { Responsiveness } \\
\text { (SCR) }\end{array}$} & 0.197 & 0.000 \\
\hline $\begin{array}{ll}\text { PRM: } & \text { 1. PRM2 } \\
& \text { (adjusting production process by adding new process modules) } \\
& \text { 2. PRM5 } \\
& \text { (rearranging production process modules so that customization sub- } \\
& \text { processes occur last) }\end{array}$ & & 0.175 & 0.000 \\
\hline $\begin{array}{l}\text { 1. DT3 } \\
\text { (reassigning production teams to different production tasks) } \\
\text { 2. DT5 } \\
\text { (using production team members that are capable of working on } \\
\text { different teams) }\end{array}$ & \multirow{2}{*}{$\begin{array}{l}\text { Operations System } \\
\text { Responsiveness } \\
\text { (OSR) }\end{array}$} & 0.224 & 0.000 \\
\hline $\begin{array}{l}\text { 1. PRM3 } \\
\text { (production process modules that can be adjusted for changing } \\
\text { production needs) } \\
\text { 2. PRM1 } \\
\text { (designing the production process as adjustable modules) }\end{array}$ & & 0.170 & 0.000 \\
\hline $\begin{array}{ll}\text { PRM: } & \text { 1. PRM5 } \\
& \text { (rearranging production process modules so that customization sub- } \\
& \text { processes occur last) } \\
& \text { 2. } P R M 2 \\
& \text { (adjusting production process by adding new process modules) }\end{array}$ & \multirow[t]{2}{*}{$\begin{array}{l}\text { Supplier Network } \\
\text { Responsiveness } \\
\text { (SNR) }\end{array}$} & 0.110 & 0.000 \\
\hline Practically NS* & & 0.077 & 0.000 \\
\hline
\end{tabular}

* Practically NS = Practically Not Significant (i.e. not practically significant to draw any substantial inferences)

Item-level regression analyses results suggest that DT3 (production teams can be reassigned to different production tasks), DT1 (production teams that can be reorganized are used in our plant), PRM2 (our products share common modules), and PRM5 (product feature modules can be added to a standard base unit) positively influence SCR on an aggregate level. Further, DT3 (production teams can be reassigned to different production tasks), DT5 (production team members are capable of working on different teams), PRM3 (production process modules can be adjusted for changing production needs), and PRM1 (our production process is designed as adjustable modules) improve OSR. Also, PRM5 (production process modules can be rearranged so that customization sub-processes occur last) and PRM2 (our production process can be adjusted by adding new process modules) positively impact SNR. Although DT positively impacts SNR on a dimension-level, the results do not support any influence of DT measures on SNR at an item-level. The italicized practices (DT3, PRM2, and PRM5) in Table 13 are the predominant practices found to repeatedly improve SCR, and OSR or SNR. This implies that firms could greatly increase SCR, OSR, and SNR by implementing these critical MBMP. These findings and implications are further discussed in the following two sections. 


\section{RESEARCH FINDINGS}

The study found direct, significant, and positive impact of MBMP on SCR. The study also found various MBMP that improve SCR and its dimensions OSR and SNR, making the study meaningful for decision makers, interesting for future researchers, and complete.

The study provides supporting evidences to the conceptual and prescriptive literature about previously untested statements regarding the relationship between MBMP and SCR. The finding supports Feitzinger and Lee's (1997) case study based argument that effective MBMP are essential for attaining cost effective responsiveness. The findings also support Tu et al.'s (2004) argument that as customers become more demanding, modularity based practices can enable firms to design and operate production systems that can meet the specific needs of customers with speed. Furthermore, the findings support Tu et al.'s (2004) argument that firms that can reconfigure and reorganize production teams quickly, without loss of efficiency, can minimize manufacturing response times without compromising on the quality of product design or process execution.

The results indicate that dynamic teaming and process modularity practices are most influential MBMP in increasing OSR, SNR, and overall SCR. The study supports Narasimhan et al.'s (2006) argument and Jacobs et al.'s (2011) finding that modular process design stimulates agility. The study however, did not find any relationship between PM and SCR.

The results reveal that the practice of reassigning production teams to different production tasks is the most important DT practice that improves responsiveness of the manufacturing and operations system of a firm, as well as the overall SCR. Furthermore, the ability to adjust production processes by adding new process modules, and the ability of production process modules to be rearranged so that customization sub-processes occur last, are the two most important PRM practices that improve both, the responsiveness of a firm's suppliers, as well as the overall SCR. The research also identified secondary practices, not as predominant as the practices listed above but significant in improving SCR and its components. While the practice of using production teams that can be reorganized is the DT practice that improves overall SCR, use of production team members that are capable of working on different teams is the DT practice that increases responsiveness of the manufacturing and operations system. Further, results revealed that use of production process modules that can be adjusted for changing production needs, and design of production process as adjustable modules, are the two PRM practices that improve OSR of a firm.

\section{RESEARCH IMPLICATIONS}

A summary of key MBMP that positively influence SCR and / or one or more of its dimensions is presented Table 14, in the increasing order of means. The mean scores (on a scale of 1 to 5, 5 being the maximum level of practice) of these key practices of responding firms in this study, suggest scope for improvement of each of these practices, in order to further improve SCR.

The current mean levels for specific MBMP in Table 14 imply that there is large scope for improvement in the practice levels for the following practices: rearranging production process modules so that customization subprocesses occur last $(\mathrm{PRM}$, mean $=2.8)$, adjusting production processes by adding new process modules $(\mathrm{PRM} 2$, mean $=3.0$ ), designing the production process as adjustable modules (PRM1, mean $=3.0$ ), using production process modules that can be adjusted for changing production needs (PRM3, mean $=3.1$ ), and using production teams in the plant that can be re-organized (DT1, mean $=3.1$ ) in order to improve corresponding impacted SCR and / or its components. Similarly, moderate scope for improvement is suggested for the practice of reassigning production teams to different production tasks $(\mathrm{DT} 3$, mean $=3.4$ ), and using production team members that are capable of working on different teams (DT5, mean $=3.5$ ) in order to improve the corresponding impacted SCR outcomes. 
Table 14 Summary of key MBMP that improve SCR, based on means

\begin{tabular}{|c|l|c|c|}
\hline$\#$ & \multicolumn{1}{|c|}{ Practice } & Mean & Outcome \\
\hline 1. & $\begin{array}{l}\text { Process Modularity practice of a firm, of rearranging production process modules so that } \\
\text { customization sub-processes occur last (PRM5) }\end{array}$ & SCR, SNR \\
\hline 2 & $\begin{array}{l}\text { Process Modularity practice of a firm, of adjusting production process by adding new } \\
\text { process modules (PRM2) }\end{array}$ & 3.0 & SCR, SNR \\
\hline 3 & $\begin{array}{l}\text { Process Modularity practice of a firm, of designing the production process as adjustable } \\
\text { modules (PRM1) }\end{array}$ & 3.0 & OSR \\
\hline 4 & $\begin{array}{l}\text { Process Modularity practice of a firm, of using production process modules that can be } \\
\text { adjusted for changing production needs (PRM3) }\end{array}$ & 3.1 & OSR \\
\hline 5 & $\begin{array}{l}\text { Dynamic Teaming practice of a firm, of using production teams in the plant that can be re- } \\
\text { organized (DT1) }\end{array}$ & 3.1 & SCR, OSR \\
\hline 6 & $\begin{array}{l}\text { Dynamic Teaming practice of a firm, of reassigning production teams to different } \\
\text { production tasks (DT3) }\end{array}$ & 3.5 & OSR \\
\hline 7 & $\begin{array}{l}\text { Dynamic Teaming practice of a firm, of using production team members that are capable } \\
\text { of working on different teams (DT5) }\end{array}$ \\
\hline
\end{tabular}

This research offers empirical evidence of the advantages of increasing process modularity and using modular team architecture practices in a firm's portfolio. Knowledge of specific MBMP that improve SCR can be helpful for practitioners to emphasize on these practices in order to improve various aspects of SCR.

The study also provides a research framework and insight for future research in the area of modularity based practices and SCR.

\section{LIMITATIONS AND FUTURE RESEARCH}

This research has extended past research in several ways, by building on past theoretical and empirical studies. Although this research has significant contributions from both theoretical and practical point of views, it also has some limitations, which are described below and which may be addressed in future research.

In this research, individual respondents (high level executives from purchasing, operations, materials, and logistics functions) in an organization were asked to respond to complex SCM issues dealing with the participants along the supply chain, including upstream suppliers and downstream customers. However, no person in an organization is in charge of the entire supply chain. Even though we have a majority of the responses (81\%) from high level executives (CEOs, VPs, and directors) who may at least have an idea of how the various process in an organization work, the use of single respondent may generate some measurement inaccuracy, more than the usual amount of random error (Koufteros, 1995). To enhance the reliability of research findings, future studies may seek to utilize multiple respondents from each participating organization. Third, this study is limited to industries (SIC codes $-22,23,25,34,35,36,37)$ used for this research. This could limit generalizability of results to other industry types. Future research may extend the study for other industry types to enhance generalizability.

Complete supply chains can be compared to better understand differences in modularity practices across supply chains operating in different industries (ex: electronic and computer, heavy industrial equipment, fashion and apparel, and consumer goods). Such comparisons can identify both, the strengths and weaknesses of each supply chain as well as the best modularity practices. Further recommendations can thus be made to improve both SCR and competitive position of firms, across different industries. Future research may expand the current theoretical framework by integrating new constructs from within and outside the field. Future studies may also test the hypothesized relationships across countries, for identification and comparison of country specific issues in modularity and responsiveness.

\section{AUTHOR INFORMATION}

Ashish A. Thatte, Ph.D., School of Business Administration, Gonzaga University, 502 E. Boone Ave., Spokane, WA 99258, USA. Corresponding author. Tel.: +1 509290 3950; Fax: +1 509313 5811. E-mail: thatte@gonzaga.edu 


\section{REFERENCES}

1. Abair, R. A. (1997), “Agile Manufacturing: Successful Implementation Strategies”, Annual International Conference Proceedings - American Production and Inventory Control Society, pp. 218-219.

2. Anderson, D. and Lee, H. (2000), "Synchronized Supply Chains: The New Frontier", www.ascet.net/ascet/wp/wpAnderson.html

3. Armstrong, J. S. and Overton, T. S. (1977), "Estimating Nonresponse Bias in Mail Surveys", Journal of Marketing Research, 14(3), pp. 396-402

4. Aron, A. and Aron, E. N. (2012), Statistics for Psychology $\left(6^{\text {th }}\right.$ Ed.), Pearson, Upper Saddle River, NJ

5. Baldwin, C. Y. and Clark, K. B. (1997), "Managing in an Age of Modularity", Harvard Business Review, 75(5), pp. 84-93.

6. Baldwin, C. Y. and Clark, K. B. (2000), Design Rules: The Power of Modularity, MIT Press, Boston, MA.

7. Burt, D. N. and Soukup, W. R. (1985), "Purchasing's Role in New Product Development", Harvard Business Review, 63, pp. 90-97

8. Chen, I. J. and Paulraj, A. (2004), "Towards A Theory of Supply Chain Management: The Constructs and Measurements”, Journal of Operations Management, 22(2), pp. 119-50.

9. Choi T.Y. and Hartley J.L. (1996), “An Exploration of Supplier Selection Practices Across the Supply Chain”, Journal of Operations Management, 14(4), pp. 333-343.

10. Christopher, M. and Peck, H. (2004), "Building the Resilient Supply Chain”, International Journal of Logistics Management, 15(2), pp. 1-13.

11. Christopher, M., Lowson, R., and Peck, H. (2004), "Creating Agile Supply Chains in the Fashion Industry", International Journal of Retail \& Distribution Management, 32(8/9), pp. 367-376.

12. Cohen, J. (1988), "Statistical Power Analysis for the Behavioral Sciences (2 ${ }^{\text {nd }}$ ed.), Lawrence Erlbaum, Hillsdale, NJ

13. Cohen, J. (1990), “Things I Have Learned (So Far)”, American Psychologist (12), pp. 1304-1312.

14. Cooper, E. (1999), "Modular Assembly Lines Are Taking Over”, Machine Design, 71(19), pp. 97-102.

15. Coronado, A. E., Lyons, A. C., Kehoe, D. F., and Coleman, J. (2004), "Enabling Mass Customization: Extending Build-To-Order Concepts to Supply Chains", Production Planning \& Control, 15(4), pp. 398411.

16. Cronbach, L. J. (1951), “Coefficient Alpha and the Internal Structure of Tests”, Psychometrika, 16, pp. 297-335.

17. Daft, R. L. and Lewin, A. Y. (1993), "Where are the Theories for the "New" Organizational Forms? An Editorial Essay", Organization Science: A Journal of the Institute of Management Sciences, 4(4), pp. 513519.

18. Dillman, D. A. (2000), Mail and Internet Surveys: The Tailored Design Method, John Wiley \& Sons, New York, NY.

19. Drucker, P. F. (1990), "The Emerging Theory of Manufacturing”, Harvard Business Review, 68(3), pp. 94 102.

20. Duclos, L. K.., Vokurka, R. J., and Lummus, R. R. (2003), “A Conceptual Model of Supply Chain Flexibility”, Industrial Management \& Data Systems, 103(6), pp. 446-456.

21. Eisenhardt, K. M. and Brown, S. L. (1998), "Time Pacing: Competing In Markets That Won’t Stand Still”, Harvard Business Review, 76(2), pp. 59-69.

22. Ernst, R. and Kamrad, B. (2000), "Evaluation of Supply Chain Structures Through Modularization and Postponement" European Journal of Operational Research, 124(3), pp. 495-510.

23. Fawcett, S. E. (1992), "Strategic Logistics in Coordinated Global Manufacturing Success", International Journal of Production Research, 30(5), pp. 1081-2000.

24. Feitzinger, E. and Lee, H. L. (1997), "Mass Customization at Hewlett-Packard: The Power of Postponement", Harvard Business Review, 75(1), pp. 116-121.

25. Fisher M.L., Raman A., and Mcclelland A.S. (2000), "Rocket Science Retailing is Almost Here: Are You Ready?", Harvard Business Review, 78(4), pp. 115-124.

26. Fuller, J. B., O’Conner, J., and Rawlinson, R. (1993), “Tailored Logistics: The Next Advantage”, Harvard Business Review, 71(3), pp. 87-98.

27. Galunic, D. C. and Eisenhardt, K. M. (2001), "Architectural Innovation and Modular Corporate Forms", Academy of Management Journal, 44(6), pp. 1229-1249. 
28. Garud, R. and Kumaraswamy, A. (1995), "Technological and Organizational Designs for Realizing Economies of Substitution", Strategic Management Journal, 16 (Special Issue), pp. 93-110

29. Gould, P. (1997), "What is Agility", Manufacturing Engineer, 76(1), pp. 28-31.

30. Gunasekaran, A. and Yusuf, Y. Y. (2002), "Agile Manufacturing: A Taxonomy of Strategic and Technological Imperatives”, International Journal of Production Research, 40(6), pp. 1357-1385.

31. Hair, J. F., Black, B., Anderson, R. E., and Tatham, R. L. (2005), Multivariate Data Analysis (6 ${ }^{\text {th }}$ Ed.), Prentice Hall, Upper Saddle River, NJ

32. Handfield, R. B. and Bechtel, C. (2002), "The Role of Trust and Relationship Structure in Improving Supply Chain Responsiveness" Industrial Marketing Management, 4(31), pp. 367-382

33. Hise, R. T. (1995), "The Implications of Time-Based Competition on International Logistics Strategies", Business Horizons, 38(5), pp. 39-46.

34. Holweg, M. (2005), “An Investigation into Supplier Responsiveness”, International Journal of Logistics Management, 16(1), pp. 96-119.

35. Holweg, M. and Pil, F. K. (2001), "Successful Build-To-Order Strategies Start with the Customer", MIT Sloan Management Review, 43(1), pp. 74-84.

36. Hoogeweegen, M. R., Teunissen, W. J. M., Vervest, P. H. M., and Wagenaar, R. W. (1999), "Modular Network Design: Using Information and Communication Technology to Allocate Production Tasks in a Virtual Organization”, Decision Sciences, 30(4), pp. 1073-1103.

37. Hopwood, K. (1995), "Modularity Transforms Manufacturing", Electronic Engineering Times, 14, pp. 72.

38. Jacobs, M., Droge, C., Vickery, S., and Calantone, R. (2011), "Product and Process Modularity's Effects on Manufacturing Agility and Firm Growth Performance", Journal of Product Innovation Management, 28(1), pp. 123-137

39. James-Moore, S. M. R. (1996), “Agility is Easy; But Effective Agile Manufacturing is not”, IEE Colloquium (Digest), 179, pp. 4.

40. Kerlinger, F. N. (1986), Foundations of Behavioural Research, 3rd Ed., Holt, Rinehart and Winston, New York.

41. Ketchen, D. J. and Hult, G. T. M. (2002), "To be Modular or not to be? Some Answers to the Question", Academy of Management Executive, 16(2), pp. 166-168.

42. Kidd, P. T. (1994), "Agile Manufacturing: Forging New Frontiers", Addison Wiley, New York, NY, U.S.A.

43. Koufteros, X. A. (1995), Time-Based Manufacturing: Developing a Nomological Network of Constructs and Instrument Development, Doctoral Dissertation, University of Toledo, Toledo, OH.

44. Lambert, D. M. and Harrington, T. C. (1990), "Measuring Nonresponse Bias in Customer Service Mail Surveys", Journal of Business Logistics, 11(2), pp. 5-25

45. Lee, H. L. (2004), “The Triple-A Supply Chain”, Harvard Business Review, 82(10), pp. 102-112.

46. Lee, H. L., Billington, C., and Carter, B. (1993), "Hewlett-Packard Gains Control of Inventory and Service through Design for Localization", Interfaces 23(4), pp. 1-11.

47. Li, S., Rao, S. Subba, Ragu-Nathan, T. S., and Ragu-Nathan, B. (2005), "Development and Validation of a Measurement Instrument for Studying Supply Chain Management Practices", Journal of Operations Management, 23(6), pp. 618-641.

48. Lorenzi, S. and Lello, A. D. (2001), "Product Modularity Theory and Practice: The Benefits and Difficulties in Implementation within a Company", International Journal of Automotive Technology and Management, 1(4), pp. 425-448.

49. Lummus, R. R., Duclos, L. K., and Vokurka, R. J. (2003), "Supply Chain Flexibility: Building a New Model", Global Journal of Flexible Systems Management, 4(4), pp. 1-13.

50. $\quad$ Marshall, M. (1996), “Oracle goes modular”, Communications Week, 631, pp. 1.

51. McCutcheon, D. M. and Raturi, A. S. (1994), "The Customization-Responsiveness Squeeze", Sloan Management Review, 35(2), pp. 89-99.

52. McGinnis M. A. and Vallorpa R. M. (1999), "Purchasing and Supplier Involvement: Issues and Insights Regarding New Product Success", Journal of Supply Chain Management, 35(3), pp. 4-15.

53. Meehan, S. and Dawson, C. (2002), "Customer Responsiveness: Getting It Fast and Right through Impatience and Intolerance", Business Strategy Review, 13(4), pp. 26-37.

54. Mertler, C. A. and Vannatta, R. A. (2009), Advanced and Multivariate Statistical Methods: Practical Application and Interpretation ( $4^{\text {th }}$ Ed.), Pyrczak Publishing, Los Angeles, CA. 
55. Mikkola, J. H. and Larsen, S. T. (2004), "Supply-Chain Integration: Implications for Mass Customization, Modularization and Postponement Strategies", Production Planning \& Control, 15(4), pp. 352-361.

56. Mikkola, J. H. R. (2003), "Modularity, Component Outsourcing, and Inter-Firm Learning”, $R$ and $D$ Management, 33(4), pp. 439-454.

57. Narasimhan, R., Swink, M., and Kim, S. W. (2006), "Disentangling Leanness and Agility: An Empirical Investigation", Journal of Operations Management, 24(5), pp.440-457.

58. Novak, S. and Eppinger, S. D. (2001), "Sourcing By Design: Product Complexity and the Supply Chain", Management Science, 47(1), pp. 189-204.

59. Nunnally, J. C. (1978), Psychometric Theory, McGraw-Hill, New York, NY.

60. O'Grady, P. (1999), The Age of Modularity: Using the New World of Modular Products to Revolutionize your Corporation, Adams and Steele, Iowa City, IA.

61. Pine, B. J., Victor, B., and Boynton, A. C. (1993), "Making Mass Customization Work", Harvard Business Review, 71(9), pp. 108-119.

62. Pine, J. B. (1999), Mass Customization: The New Frontier in Business Competition, Harvard Business School Press Books, Cambridge, MA, USA

63. Prater, E., Biehl, M., and Smith, M. A. (2001), "International Supply Chain Agility", International Journal of Operations \& Production Management, 21(5/6), pp. 823-840.

64. Reichhart, A. and Holweg, M. (2007), "Creating The Customer-Responsive Supply Chain: A Reconciliation Of Concepts”, International Journal of Operations \& Production Management, 27(11), pp. 1144-1172.

65. Ricker, F. and Kalakota, R. (1999), “Order Fulfillment: The Hidden Key to E-Commerce Success”, Supply Chain Management Review, 11(3), pp. 60-70.

66. Robertson, D. and Ulrich, K.T. (1998), "Planning for Product Platforms," Sloan Management Review, 39(4), pp. 19-31.

67. Salvador, F., Forza, C., and Rungtusanatham, M. (2002), "Modularity, Product Variety, Production Volume, and Component Sourcing: Theorizing Beyond Generic Prescriptions", Journal of Operations Management, 20(5), pp. 549-575.

68. Sanchez, R. (1999), "Modular Architectures in the Marketing Process", Journal of Marketing, 63, pp. 92111.

69. Sanchez, R. (2000), "Modular Architectures, Knowledge Assets and Organizational Learning: New Management Processes for Product Creation", International Journal of Technology Management, 19(6), pp. 610-629.

70. Sanchez, R. and Collins, R. P. (2001), "Competing - and Learning - in Modular Markets”, Long Range Planning, 34(6), pp. 645-667.

71. Sanchez, R. and Mahoney, J. T. (1996), "Modularity, Flexibility, and Knowledge Management in Product and Organization Design”, Strategic Management Journal, 17(4), pp. 63-76.

72. Schilling, M. A. (2000), "Toward a General Modular Systems Theory and its Application to Inter-firm Product Modularity", Academy of Management Review, 25(2), pp. 312-334.

73. Schilling, M. A. and Steensma, H. K. (2001), "The Use of Modular Organizational Forms: An IndustryLevel Analysis", Academy of Management Journal, 44(6), pp. 1149-1168.

74. Sharifi, H. (1998), “Agile Manufacturing - A Structured Perspective”, IEE Colloquium (Digest), 213 , pp. 5/1-5/4.

75. Simchi-Levi, D., Kaminsky, P., and Simchi-Levi, E. (2008), Designing and Managing the Supply Chain, $3^{\text {rd }}$ Ed., Irwin McGraw-Hill, New York, NY.

76. Slack, N. (1991), The Manufacturing Advantage, Mercury Books, London.

77. Stalk, G., Evans, P. Shulman, L. E. (1992), "Competing on Capabilities: The New Rules of Corporate Strategy”, Harvard Business Review, 70(2), pp. 54-65

78. Starr, M. K. (1965), “Modular Production--A New Concept”, Harvard Business Review, 43(6), pp. 131142.

79. Suzik, H. A. (1999), “GM Announces Modularity Project” Quality, 38(5), pp. 14.

80. Swaminathan, J. M. (2001), "Enabling Customization Using Standard Operations”, California Management Review, 43(3), pp. 125-135

81. Thatte, A., Rao, S., and Ragu-Nathan, T. S. (2012), "Impact of SCM Practices of a Firm on Supply Chain Responsiveness and Competitive Advantage of a Firm, Working Paper 
82. Tu, Q. (1999), Achieving Mass Customization through Technology Application and Absorptive Capacity A Customer-Oriented Framework, Doctoral Dissertation, University of Toledo, Toledo, OH.

83. Tu, Q., Vonderembse, M. A., Ragu-Nathan, T. S., and Ragu-Nathan, B. (2004), "Measuring ModularityBased Manufacturing Practices and Their Impact on Mass Customization Capability: A Customer-Driven Perspective", Decision Sciences, 35(2), pp. 147-168.

84. Ulrich, K. (1995), "The Role of Product Architecture in the Manufacturing Firm”, Research Policy, 24(3), pp. 419-440

85. Ulrich, K. and Tung, K. (1991), "Fundamentals of Product Modularity", Proceedings of the 1991 ASME Design Engineering Technical Conferences - Conference on Design/Manufacture Integration, Miami, FL.

86. Van Hoek, R. I. and Weken, H. A. M. (1998), "The Impact of Modular Production on the Dynamics of Supply Chains", International Journal of Logistics Management, 9(2), pp. 35-50.

87. Van Hoek, R. I., Harrison A., and Christopher, M. (2001), "Measuring Agile Capabilities in the Supply Chain”, International Journal of Operations and Production Management, 21 (1/2), pp. 126-147.

88. Weick, K. E. (1990), “Technology as Equivoque: Sensing in New Technologies”, Technology and Organizations, edited by Paul S. Goodman, Lee S. Sproull, and Associates, Jossey-Bass, San Francisco, pp. $1-44$.

89. Williamson, P. J. (1991), "Supplier strategy and customer responsiveness: Managing the links", Business Strategy Review, 2(2), pp. 75-91.

90. Wu, B. (2001), “A Unified Framework of Manufacturing Systems”, Industrial Management and Data Systems, 101(9), pp. 446-469.

91. Yang, B., Burns, N. D., and Backhouse, C. J. (2004), "Postponement: A Review and an Integrated Framework”, International Journal of Operations and Production Management”, 24(5), pp. 468-487.

92. Zimmerman, M. R. (2003), "Storage, Modular and Cubed", eWeek, 10. 


\section{APPENDIX A: INSTRUMENT FOR MBMP AND SCR CONSTRUCTS}

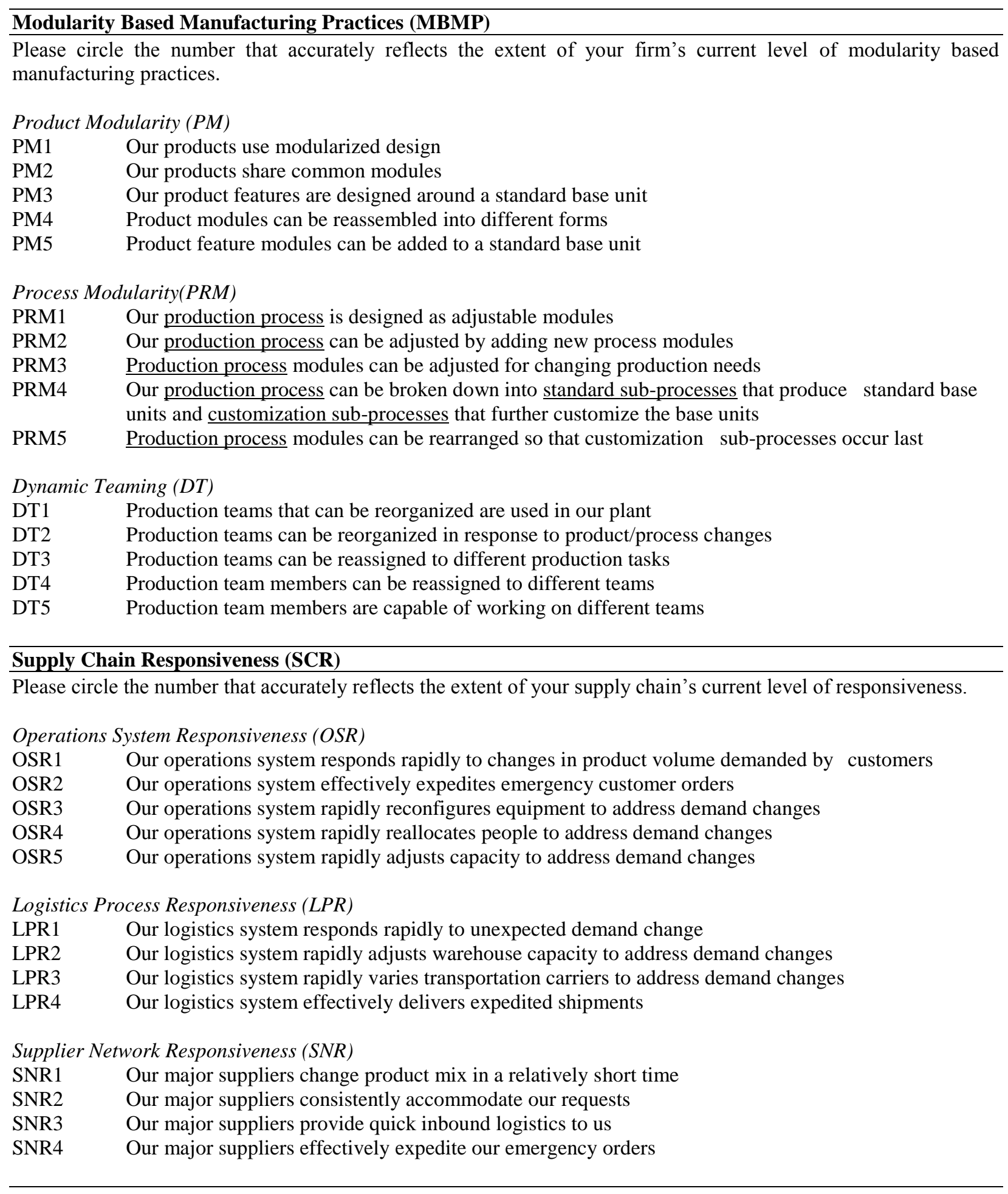


APPENDIX B: DEMOGRAPHIC DATA OF RESPONDENTS (SAMPLE SIZE 294)

\begin{tabular}{lccc}
\hline Variables & Total Responses & First-wave & Second and third wave \\
\cline { 2 - 4 } & Frequency (\%) & Frequency (\%) & Frequency (\%) \\
\hline Industry - SIC (278) & & & \\
SIC 22 & $0(0.0 \%)$ & $0(0.0 \%)$ & $0(0.0 \%)$ \\
SIC 23 & $4(1.4 \%)$ & $2(2.3 \%)$ & $2(1.1 \%)$ \\
SIC 25 & $7(2.5 \%)$ & $2(2.3 \%)$ & $5(2.6 \%)$ \\
SIC 34 & $29(10.4 \%)$ & $9(10.3 \%)$ & $20(10.5 \%)$ \\
SIC 35 & $28(10.1 \%)$ & $7(8.1 \%)$ & $21(11.0 \%)$ \\
SIC 36 & $110(39.6 \%)$ & $36(41.4 \%)$ & $74(38.7 \%)$ \\
SIC 37 & $26(9.4 \%)$ & $8(9.2 \%)$ & $18(9.4 \%)$ \\
Other & $74(26.6 \%)$ & $23(26.4 \%)$ & $51(26.7 \%)$ \\
& & & \\
Number of employees $(291)$ & & $8(4.0 \%)$ \\
1-50 & $12(4.1 \%)$ & $4(4.4 \%)$ & $14(7.0 \%)$ \\
51-100 & $20(6.9 \%)$ & $6(6.6 \%)$ & $26(13.0 \%)$ \\
100-250 & $35(12.0 \%)$ & $9(9.9 \%)$ & $26(13.0 \%)$ \\
251-500 & $10(11 \%)$ & $18(9.0 \%)$ \\
501-1000 & $36(12.4 \%)$ & $7(7.7 \%)$ & $108(54.0 \%)$ \\
Over 1000 & $25(8.6 \%)$ & $55(60.4 \%)$ & \\
Job title (290) & $163(56.0 \%)$ & & $20(10.1 \%)$ \\
CEO/President & & & $93(47.0 \%)$ \\
Vice President & $31(10.7 \%)$ & $11(12.0 \%)$ & $50(25.3 \%)$ \\
Director & $130(44.8 \%)$ & $37(40.2 \%)$ & $35(17.7 \%)$ \\
Manager & $73(25.2 \%)$ & $23(25.0 \%)$ &
\end{tabular}




\section{NOTES}

